\title{
Engineering Standards: An Introduction for Electrical and Computer Engineering Students
}

\author{
John O. Attia, \\ Dhadesugoor Vaman, \\ Matthew N. O. Sadiku, \\ Department of Electrical and Computer Engineering \\ Prairie View A\&M University \\ Prairie View, TX 77446
}

\begin{abstract}
Engineering standards are summaries of industrial best practices. The specifications are written in terms of functional, mechanical and electrical aspects that allow proper usage of available components to build a system. Standards may also be regarded as codified guidelines that define how tests should be performed, and how products are to be designed. Standards are created by bringing together experience and expertise of stakeholders on specific issues. Standards protect public health and safety, improve product quality, help to advance the growth of new technologies, and foster international trade. It is important that students get familiar with standards while in school.
\end{abstract}

Keywords: Engineering standards, computer engineering

\section{Introduction}

\section{Why Standards?}

International Organization for Standardization (ISO) defines a standard as " a document that provides requirements, specifications, guidelines or characteristics that can be used consistently to ensure that materials, products, processes and services are fit for their purpose." Today, there are standards for programming languages, electrical interfaces, and communications protocols. The purpose of standards is to establish definitions, test procedures, and rating structure to allow the comparison of one product with another on an equitable basis.

Standards can be grouped according to the following categories: (i) process standards, (ii) standard test methodologies, and (iii) performance standards. Process standards are standards that describe the general system or 
a way of doing things. Standard test methodology specifies a test to be performed, the test protocol to be followed to evaluate the physical properties or performance levels of a product. The Performance standard describes the performance attributes, usually for a single device category.

Standards allow a user of a technology product to be able to replace Vendor A product with Vendor B product and the technology should work with no other changes as long as both Vendor A and Vendor B products conform to the same standard. This is termed as inter-operability. In addition, standards allow multi-vendor products of the same technology to communicate with each other. This is termed inter-working. The standard defines the necessary interface which is very effective to achieve interworking. Because of standards, it is possible for a 100-watt light bulb to fit the socket of all table lamps. In addition, through engineering standards, a CD can be played in a car, or in a portable CD player. Table 1 shows the Element/product/system with their corresponding engineering standards. Standards are not limited to electronics; they apply to other things such as materials, cabinets, etc.

Table 1 Element/product/system and their corresponding engineering standard

\begin{tabular}{|l|l|l|}
\hline Element/Product/System & \multicolumn{1}{|c|}{$\begin{array}{c}\text { Engineering } \\
\text { Standard }\end{array}$} & \multicolumn{1}{|c|}{ Comments } \\
\hline $\begin{array}{l}\text { Standard Mounts for } \\
\text { Sight Bulbs (Edison } \\
\text { Screw) }\end{array}$ & $\begin{array}{l}\text { ANSI C81.64 } \\
\text { and IEC 60061 }\end{array}$ & Specifies lamp mount types. \\
\hline Standard Resistor Values & $\begin{array}{l}\text { Electronic } \\
\text { Industry } \\
\text { Association } \\
\text { (EIA) }\end{array}$ & $\begin{array}{l}\text { The EIA "E" series specify preferred } \\
\text { resistance values for various tolerances. } \\
\text { E12 for 10\% tolerance and E24 for 5\% } \\
\text { tolerance. }\end{array}$ \\
\hline $\begin{array}{l}\text { Universal Serial Bus } \\
\text { (USB) }\end{array}$ & IEC 62680 & $\begin{array}{l}\text { Defines the connectors, cables, and } \\
\text { communications protocols used in a bus } \\
\text { for connection and communication } \\
\text { between computers and electronic } \\
\text { devices. }\end{array}$ \\
\hline $\begin{array}{l}\text { C++ Programming } \\
\text { Language }\end{array}$ & $\begin{array}{l}\text { ISO/IEC } \\
14882: 2011\end{array}$ & $\begin{array}{l}\text { General purpose programming language } \\
\text { that was standardized, ratified and } \\
\text { published by ISO in 2011. }\end{array}$ \\
\hline $\begin{array}{l}\text { One-phase 3-wire } 60 \mathrm{~Hz} \\
\text { Low Voltage: } 120 / 240 \mathrm{~V}\end{array}$ & IEC 60038 & $\begin{array}{l}\text { Defines a set of standard voltage for low } \\
\text { voltage AC electricity supply system. }\end{array}$ \\
\hline
\end{tabular}

A report from the US Congress' Office of Technology Assessment indicated that standards are important for national economic growth and innovation. In industry, good standards: (i) promote market efficiency and expansion, (ii) foster international trade, (iii) encourage competition and 
lower barriers to market entry, (iv) diffuse new technologies, (v) protect consumers against unsafe products, (vi) serve to increase product quality, and (vii) allow for interchangeability of parts.

The Accreditation Board for Engineering and Technology (ABET) Criterion 5 states that: "Students must be prepared for engineering practice through a curriculum culminating in a major design experience based on the knowledge and skills acquired in earlier course work and incorporate appropriate engineering standards and multiple realistic constraints." This criterion assumes that students are familiar with engineering standards while working on their senior design projects.

\section{How Are Engineering Standards Made?}

An engineering standard is created by bringing together experience and expertise of stakeholders on a specific issue. The standard created is the result of a consensus of stakeholders involved in the development. The stakeholders may consist of experts in the technical area, product users, regulatory agencies, manufacturers and other interested parties.

Standards are typically developed when a group of organizations want to offer a commercial product. Standards ensure that no product is designed with supply chain of components only from one vendor. For example, any product that uses INTEL chips also can use AMD chips. Technically one does not need a standard if only one vendor develops a commercial product. Standards bodies are extremely careful to make sure multiple vendors participate in the development of the same product so that the end users can have choices in where they can procure a product.

As an example, let us consider how a standard is initiated in IEEE. A group of individuals or committee decides that a standard is needed to provide uniformity or safety for the industry. The committee looks for a sponsor in one of the IEEE technical societies. Since the sponsor takes responsibility, there must be interest and technical competence within the sponsoring society. The next step is to fill out the project authorization request (PAR) form and submit it to IEEE Standards Board. The PAR is submitted to New Standards Committee (NesCom). Once the NesCom approves the PAR, the project is recognized by IEEE Standards Association Standards Board (SASB) and work may commence on it. The time between the approval of PAR and the completion of the standard may take up to four years.

Further development of the standard requires a working group (WG), which is established by due process. The WG consists of individuals representing the various aspects of the subject. The basic steps taken by the WG involves: (1) understand the purpose and scope of the PAR; (2) examine related publications and standards; (3) determine "state-of-art;" (4) 
draft an outline; (5) add the text; (6) finalize the document. When all these steps have been taken, the final draft is ready for balloting. A $100 \%$ approval is not required. Finally, the approved standard is published by IEEE.

\section{Some Standards Organizations}

Standards are developed by several organizations including:

ISO (International Standards Organization), headquarters in Geneva, Switzerland, was formed in 1947. International standards are main focus of the ISO. The organization promotes worldwide commercial and industrial standards. It has over 160 national members. Each national member represents a country. The standards are published by ISO and made available through national standards bodies.

International Telecommunication Union (ITU), headquarters in Geneva, Switzerland, is one of specialized agencies of the United Nations that focus on issues related to information and communication technologies. ITU coordinates the shared global use of the radio spectrum, and the organization assists in assigning satellite orbits. ITU has over 190 member countries, and over 700 private-sector entities and academic institutions. Standardization is one of the major activities of ITU and that part of ITU work used to be done by International Telephone and Telegraph Consultative Committee (CCITT).

International Electrotechnical Commission (IEC) has approximately 82 member nations. Founded in 1906 and headquartered in Geneva, the IEC is the leading organization for the preparation and publication of international standards for all electrical, electronic, and related technologies. IEC standards cover a broad range of technologies such as power generation, distribution of electricity to industries and households, medical technologies, fiber optics, batteries, solar energy, and nanotechnology. The IEC is one of three global sister organizations (IEC, ISO, ITU) that develop International Standards for the world. There is a strong collaboration between IEC, ISO and ITU.

American National Standards Institute (ANSI), headquarters in Washington, D.C., is the national standard body in the United States. It was established in 1918 to enhance both the global competitiveness of U.S. business and the U.S. quality of life by promoting and facilitating voluntary consensus standards and conformity assessment systems, and safeguarding their integrity. ANSI is also actively engaged in accrediting programs that assess conformance to standards. 
Standard Council of Canada (SCC) , located in Ottawa, has a twofold mission: (i) to lead and facilitate the development and use of national and international standards, and (ii) to conduct accreditation services that enhance Canada's competitiveness. The Council's work falls into three major areas: (i) standards, (ii) accreditation services, and (iii) policy and stakeholder relations. The Standards Council of Canada has a 13-member governing council and a staff of approximately 90. It has a seat on the ISO's governing Council.

Institute of Electrical and Electronics Engineers (IEEE) was formed in 1963 by the merger of the two institutions, the Institute of Radio Engineers and the American Institute of Electrical Engineers. With its headquarters located in New York City, its purposes is the advancement of the theory and practice of electrical, electronics, communications, and computer engineering, as well as computer science and other branches of engineering. It is also a leading standards development organization for the development of industrial standards in a broad range of disciplines. The IEEE has more than 10,000 participants in over 90 countries that support the IEEE standards development work. The IEEE Standards Association has published more than 900 standards that are now in use.

Standards development organizations such as ANSI and IEEE should not be confused with certification/testing groups such as SCC and UL. Certification groups test products to see if they meet some specifications. They are not standard organizations.

\section{Different Types Of Standards}

There are different types of standards. Some are governmentmandated, while some are voluntary. For mandated standards, there are penalties for not adhering to the standard.

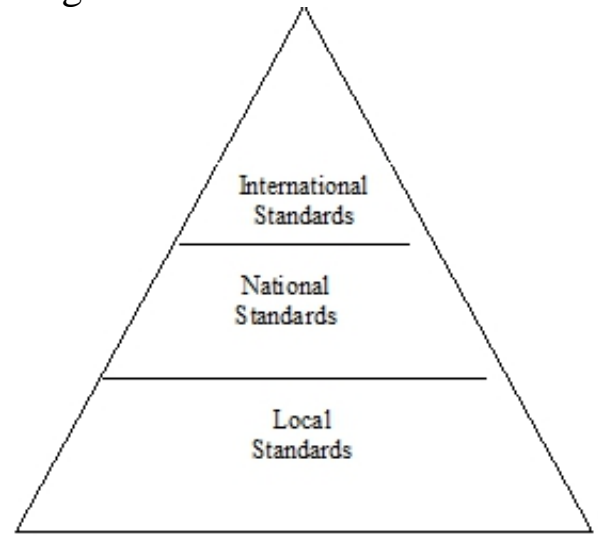

Fig. 1 Different types of standards. 
As shown in Figure 1, standards can be classified as local, national or international. Local standards are developed by companies when national or international standards are not available. Many organizations and companies (such as IBM) produce standards. For example, the United States Department of Defense (DoD) develops standards, termed Military Standard (MIL STD) and uses them. Some of these DoD standards made their way into national standards. Most North American-based corporations in the petroleum and chemical industry use in-house standards as well national and international standards.

National standards are developed by national standards organizations such as ANSI for the United States, and SCC for Canada. As local standards become enhanced by national bodies, they become national standards. A survey conducted in 1993 by ANSI found that there were 89,000 standards in the United States, 88,000 in the Russian Federation, 18,300 in France, 8,800 in Japan, and 6,000 in Canada.

International standards are developed by international standards organization such as ISO and IEC. International standards help to harmonize standards in different parts of the world. They allow people in one nation to be able to communicate with people in other nations. Each day the world is becoming more global marketplace. As corporations become global, the need for international standards becomes more acute. A standard in one country does not automatically qualify a product in another country because each country has a set of its own standards.

\section{Examples Of Engineering Standards}

There are over 1 million standards worldwide. IEEE 802.3 Carrier Sense Multiple Access/Collision Detections and its variants has been the most successful standard in terms of commercial deployment worldwide since 1985. Below are some newer engineering standards.

\section{(a) Communications}

The IEEE Standard 802.11 goes by the popular name of Wi-Fi. The standard makes the speed of local-area networks to be 54 megabits per second. The IEEE Standard $802.11 \mathrm{~g}$ allows a person to share documents $\mathrm{t}$ the speed of $54 \mathrm{Mb} / \mathrm{s}$, up from $11 \mathrm{Mb} / \mathrm{s}$ called for in the Standard 802.11b on a wireless local-are network. Another standard 802.11a allows devices to operate in the 5-gigahertz band rather than in the lower 2.4-GHz band where there can be interference from devices such as cordless telephones and microwave ovens. 
The IEEE Standard 802.15.4 allows one to play video games with wireless controllers. It provides a common framework for small, low datarate wireless devices, such as video-game controllers, to connect to a gameplaying console at 10 to 250 kilobits per second at distance of 10 meters or less.

The IEEE Standard 1512 sets up guidelines for each emergency allowing each emergency responder to communicate with others. Also the standard outlines a common set of data fields to communicate details of an accident uniformly, ensuring that the right people and equipment arrive on the scene. The standard allows the local police, fire department and emergency medical services to arrive at a scene of an accident, and provide services.

\section{(b) Computers and Networking}

The IEEE Standard 2001 is for website reliability. This Standard was developed with Consumer Unions and was released in 2002. It specifies that every web page should have a link that names the organization supplying the information, how to contact it, and a statement that your privacy will be protected. The standard also has guidelines for creating web sites that people with disabilities can use. Google and the European Union were involved in adopting the standard.

The IEEE Standard 1073 specifies how medical electronic equipment are plugged into a network, and also how data are captured, processed, and archived in hospital' computer systems without extra software, additional hardware, or loss of information. The standard allows medical personnel to automatically record readings from several different kinds of diagnostic equipment into a patient's chart. It avoids manually recording readings, thus cutting down errors in transferring medical information.

\section{(c) Power Generation, Transmission and Distribution}

IEEE Standard 1547 outlines the requirements for running distributed generators when power is out. The standard also specifies what needs to be done for the distributed generator to supply excess power to the grid. The IEEE Standard 1547 allows the grid to operate in both directions (grid to supply power to a consumer, and a consumer to supply power to the grid).

\section{Conclusion}

The Accreditation Board for Engineering and Technology (ABET) Criterion 5 requires students to complete major design projects that 
incorporate appropriate engineering standards. Students should be familiar with the engineering standards relevant to their capstone design projects and incorporate the dictates of the standards in their projects. Standards enhance learning by pointing to students best industrial practices. Since standards are updated frequently to keep pace with new technological developments, it is important that engineers stay current on new standards and practices.

\section{References:}

1. F. Coallier, "Standards, Agility, and Engineering," Computer, Sept. 2007, pp.100-102.

2. J. R. Goldberg, "Standards in Capstone Design Courses and the Engineering Curriculum," IEEE Pulse, Sept./Oct. 2012, pp. 42-44.

3. B. C. Johnson, D. G. Dunn, and R. Hulett, "Seeking global harmony in standards," IEEE Industry Applications Magazine, Jan./Feb. 2004, pp.14-23.

4. K. Reilly, “A U. S. Perspective on Standards Development," IEEE Communications Magazine, Jan. 1994, pp. 30-36

5. S. Kunst and J. R. Godberg, "Standards Education in Senior Design Courses," IEEE Engineering in Medicine and Biology Magazine, pp. $114-117$, July/August 2003.

6. E. Vonderheid, "Standards Hidden in Plain Sight", IEEE: The Institute, pp. 8-9, March 2004. 